\title{
Intracranial Mycotic Aneurysm after Left Ventricular Assist Device Implantation Treated with Trans-arterial Embolization via the Brachial Artery: A Case Report
}

\author{
Takayuki FunATSU, ${ }^{1}$ Tatsuya ISHIKAWA, ${ }^{1}$ Koji YAMAGUCHI, ${ }^{1}$ Seiichiro EGUCHI, ${ }^{1}$ \\ Go MatsuOKA, ${ }^{1}$ Keisuke MoriYa, ${ }^{1}$ Hiroshi NAKano, ${ }^{1}$ Shuhei Morita, ${ }^{1}$ \\ Tomoko SHIWA, ${ }^{1}$ Takahiro HORI, ${ }^{1}$ and Takakazu KAWAMATA ${ }^{1}$
}

${ }^{1}$ Department of Neurosurgery, Tokyo Women's Medical University, Tokyo, Japan

\begin{abstract}
Implantation of left ventricular assist device (LVAD) is widely performed in patients with end-stage chronic heart failure. Infection and stroke are major complications after LVAD implantation. However, the incidence of intracranial mycotic aneurysm after LVAD implantation is rare, and with no standard of care. In this study, we describe a case of an intracranial mycotic aneurysm after LVAD implantation that was successfully treated with trans-arterial embolization (TAE) with N-butyl 2-cyanoacrylate (NBCA) via the brachial artery. A 49-year-old man with a history of implantation of LVAD for ischemic cardiomyopathy was admitted to our institution. He had infectious endocarditis and was administered systemic antibiotics. At 3 weeks after admission, intracranial mycotic aneurysm of the left posterior parietal artery was detected during a diagnostic examination for asymptomatic intracranial hemorrhage. Anticoagulant therapy was administered to prevent thromboembolic complications of LVAD implantation. Under local anesthesia, TAE with NBCA was performed via the brachial artery because of the tortuous anatomy of the origin of the innominate artery and implant of the aortic arch. The aneurysm was completely obliterated. The patient was discharged without neurological deficits. TAE using NBCA could be an effective modality for the treatment of intracranial mycotic aneurysm after LVAD implantation.
\end{abstract}

Keywords: heart-assist devices, intracranial aneurysm, therapeutic embolization, brachial artery

\section{Introduction}

The implantation of left ventricular assist device (LVAD) is widely performed in patients with end-stage chronic heart failure, as a bridge-to-transplantation therapy ${ }^{1)}$ or long-term myocardial surrogate. ${ }^{2)}$ Moreover, it has been reported to improve prognosis for these patients. ${ }^{3)}$ Infection is a major complication after LVAD implantation, ${ }^{4)}$ resulting in infective endocarditis (IE). ${ }^{5)}$ Nevertheless, intracranial mycotic aneurysm could occur after LVAD implantation. Although

Received July 27, 2020; Accepted January 4, 2021

Copyright $@ 2021$ The Japan Neurosurgical Society This work is licensed under a Creative Commons AttributionNonCommercial-NoDerivatives International License. trans-arterial embolization (TAE) for the intracranial mycotic aneurysm is often performed, there are limited reports focusing on the patient's condition after LVAD implantation. ${ }^{6-10)}$ In this study, we describe a case of an intracranial mycotic aneurysm after LVAD implantation in a patient who was successfully treated with TAE using N-butyl 2-cyanoacrylate (NBCA) via the brachial artery.

\section{Case Report}

A 49-year-old man with a medical history of implantation of continuous-flow LVAD for ischemic cardiomyopathy due to Stanford type A acute aortic dissection was admitted to our institution with fever and lumbar pain. He had also undergone Bentall procedure, coronary artery bypass graft surgery, and 
aortic arch stenting as an initial treatment of acute aortic dissection. As gram-positive cocci (Streptococcus sanguinis) were detected in blood culture, the patient was diagnosed with IE and administered a systemic broad-spectrum antibiotic, along with anticoagulant therapy to maintain the international normalized ratio between 2.0 and 2.5. In addition, antiplatelet therapy was administered to prevent thromboembolic complications. Three weeks after admission, asymptomatic intracranial hemorrhage was detected incidentally in the left parietal lobe (Fig. 1A). Enhanced brain CT showed an enhancing lesion inside the hematoma (Fig. 1B). Subsequently, digital subtraction angiography (DSA) was performed and revealed a saccular aneurysm of the left posterior parietal artery, approximately $2.3 \mathrm{~mm}$ in diameter (Fig. 1C). Considering the medical history of the patient, this lesion was suspected to be intracranial mycotic aneurysm. We performed TAE to prevent re-bleeding from the lesion. An endovascular procedure via the trans-femoral approach was considered difficult owing to the tortuous anatomy of the origin of the innominate artery and implant of the aortic arch after a past thoracic aortic surgery (Fig. 1D). Therefore, we selected the transbrachial approach to access the aneurysm.

\section{Endovascular treatment}

A 4-F FUBUKI dilator kit (ASAHI INTECC, Aichi, Japan) was introduced into the right brachial artery
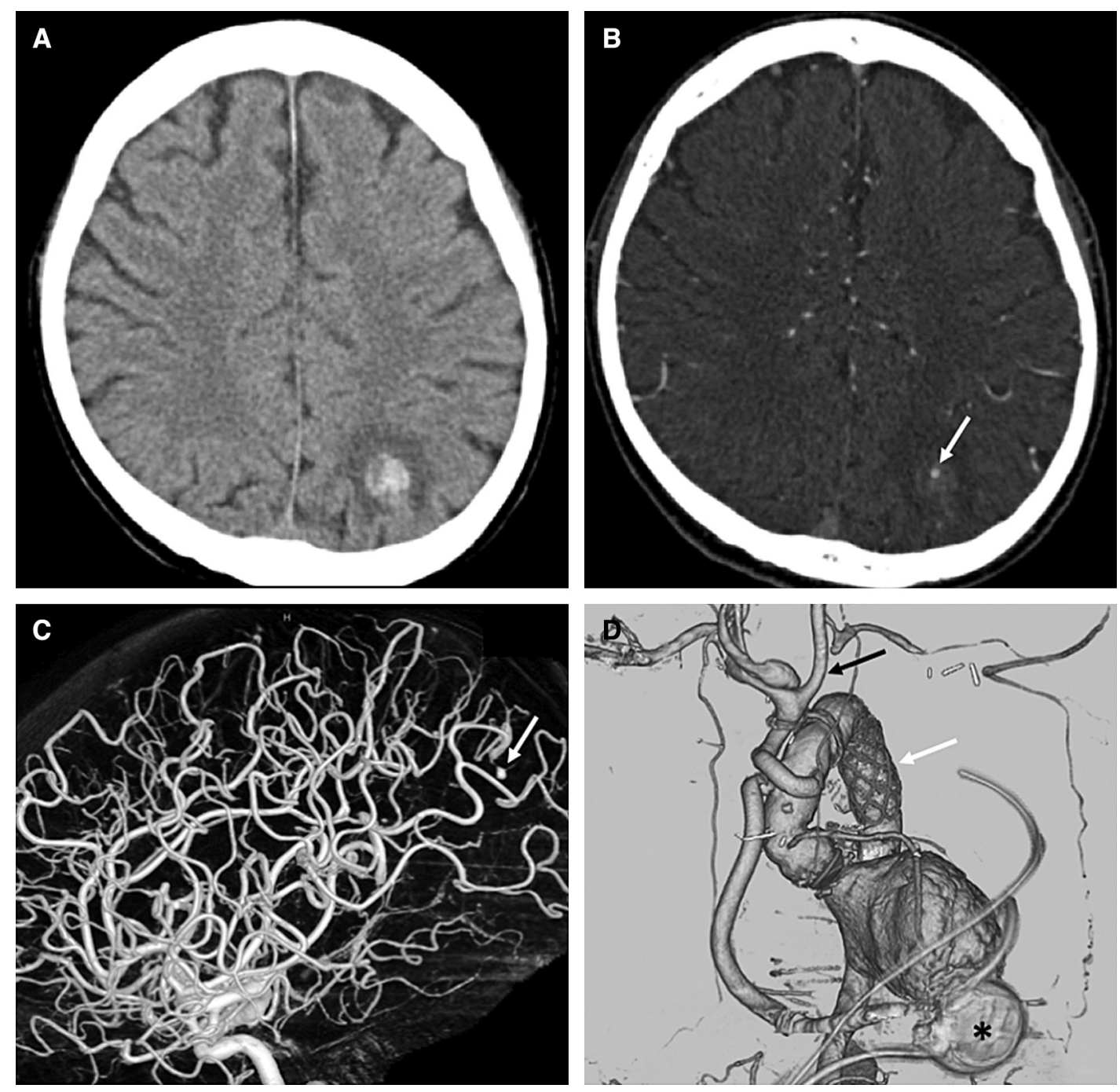

Fig. 1 CT shows a high-density area at the left parietal lobe (A). Enhanced CT shows an enhancing lesion (white arrow) inside the hematoma (B). Three-dimensional rotation angiography shows a saccular aneurysm (white arrow) of the left posterior parietal artery (C). The frontal view of three-dimensional CT shows a left ventricular assist device (asterisk) and a previous implant (white arrow). The left common carotid artery (black arrow) branches directly from the brachiocephalic artery (D). 
under local anesthesia. Ultrasound guidance was needed for the brachial artery puncture because pulsation of the artery could not be confirmed due to a continuous-flow LVAD. After heparin administration and maintaining the activated coagulation time of $>200$ sec, the guiding sheath was introduced into the left internal carotid artery. A 3.4-F TACTICS (Technocrat Corporation, Aichi, Japan) and a DeFrictor Nano catheter (Medico's Hirata, Osaka, Japan) were coaxially inserted, and the microcatheter was introduced into the proximal side of the aneurysm (Fig. 2A). "While introducing the microcatheter, a wire perforation occurred, and DSA revealed an extravasation from the parent vessel proximal to the aneurysm (Fig. 2B). The extravasation was caused by the manipulation of the parent vessel—speculated of having a pathologically fragile wall-with a microguidewire."

After an injection of $25 \%$ NBCA through the microcatheter $(0.14 \mathrm{~mL}$ in total), the aneurysm was embolized and the extravasation also disappeared (Figs. 2C and 2D).

\section{Postoperative course}

After the procedure, no neurological deficit was observed in the patient. However, a small amount of subarachnoid hemorrhage was detected on a post-operative CT scan (Fig. 3). Oral administration of a sensitive antibiotic was continued postoperatively for the treatment of LVAD-associated IE. After the infection was controlled, the patient was
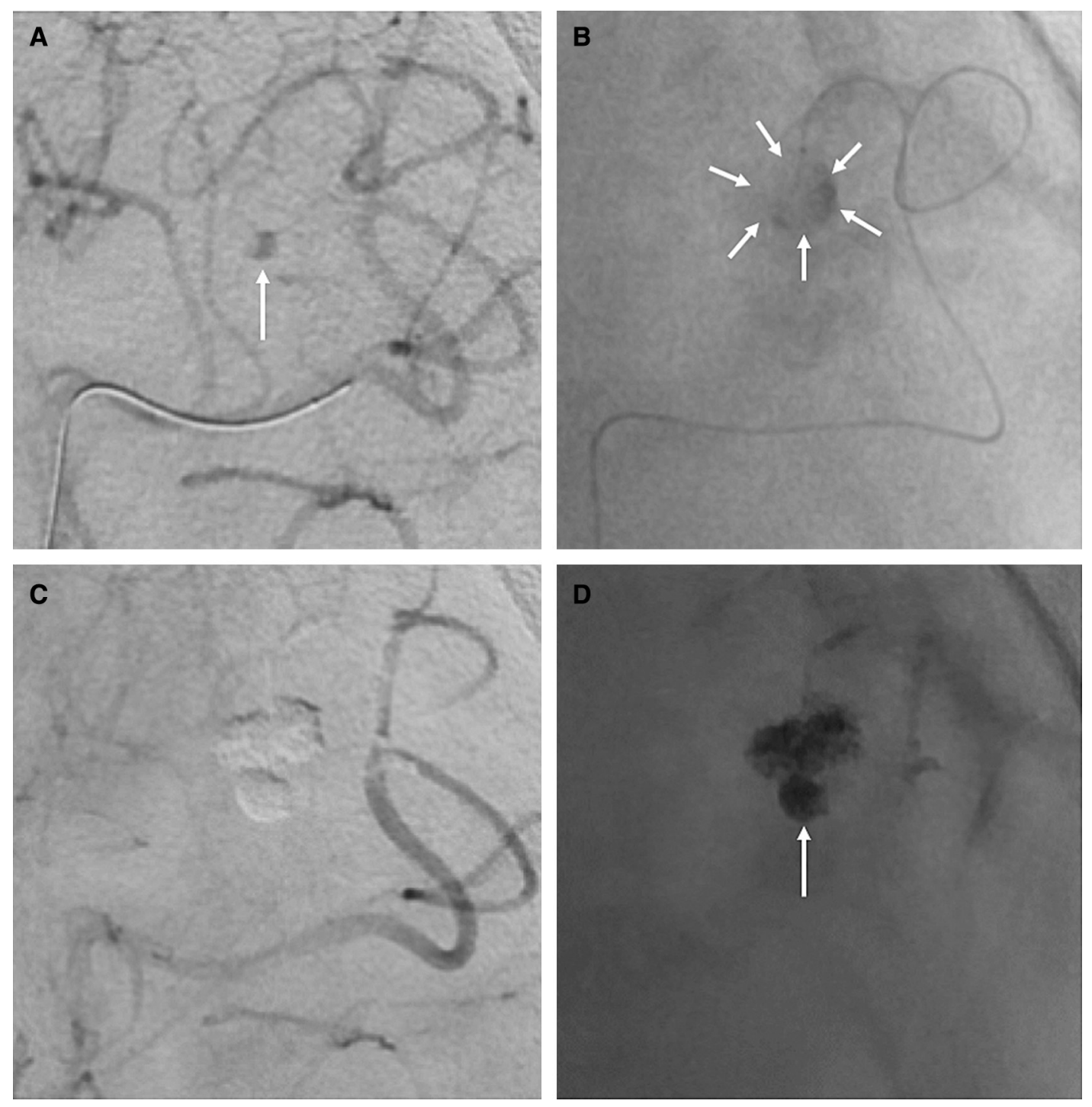

Fig. 2 Lateral view of the left internal carotid artery angiogram and aneurysm (arrow) (A). Extravasation (arrows) after the introduction of the microcatheter (B). Disappearance of the aneurysm and extravasation after $\mathrm{N}$-butyl 2-cyanoacrylate (NBCA) injection (C). Intraoperative craniogram shows NBCA into the aneurysm (arrow) (D). 
discharged at 62 days after surgery and continued receiving the antibiotic agent.

\section{Discussion}

Intracranial mycotic aneurysm arises from weakened cerebral arterial walls and septic emboli mainly

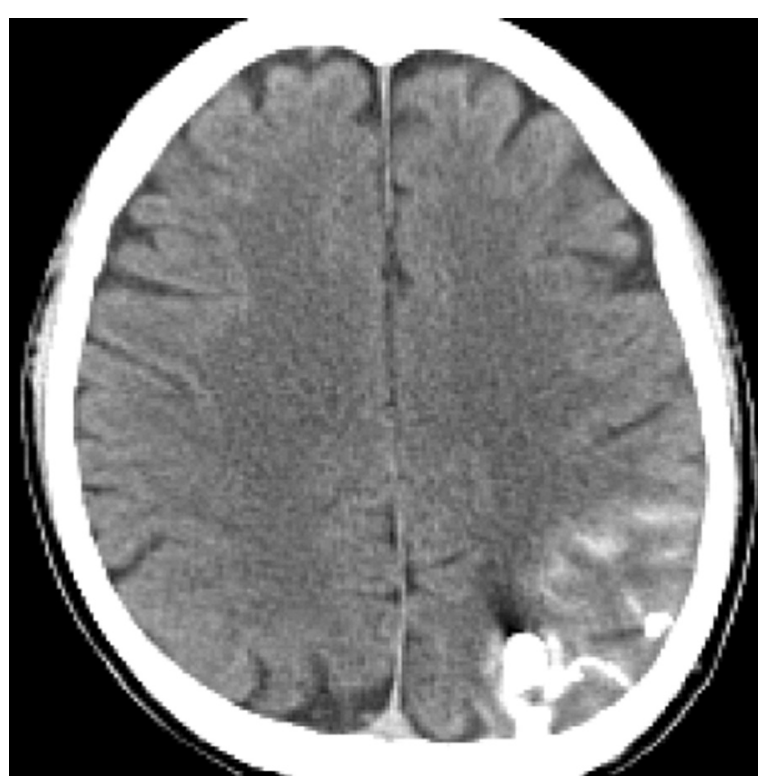

Fig. 3 Postoperative CT shows a cast of the N-butyl 2-cyanoacrylate and a small amount of subarachnoid hemorrhage. resulting from IE. ${ }^{11)}$ Intracranial mycotic aneurysms have been detected in $8.9 \%$ of patients with IE who have undergone cerebral angiography; therefore, it is not considered a rare lesion. ${ }^{12)}$ The incidence of intracranial mycotic aneurysm after LVAD implantation was reported to be $0.5 \%-2.7 \%{ }^{13-16)}$ Inflammation is controlled with sensitive antibiotic treatment following LVAD implantation because of the high risk of drive infection. Therefore, the incidence of IE and the associated mycotic aneurysm is not high.

Singla et al. reported on the treatment practices in managing infectious intracranial aneurysms in the United States between 2002 and 2011. They described that $18.6 \%$ of all cases underwent neurosurgical interventions, and the mortality rate was $24.7 \% .{ }^{17)}$ The findings from earlier reports of intracranial mycotic aneurysms after LVAD implantation are listed in Table 1. According to these reports, $67 \%$ of the cases underwent neurosurgical interventions, and the mortality rate was $>33 \% .{ }^{17)}$ It is difficult to compare the data because of the small number of cases of intracranial mycotic aneurysms after LVAD implantation. Therefore, there is a possibility that prognosis of mycotic aneurysms after LVAD implantation was poorer than that of typical intracranial mycotic aneurysm. Given that the patients after LVAD implantation have clinical features, such as receiving anticoagulation therapy and having

Table 1 Summary of the past reports of intracranial mycotic aneurysm after LVAD implantation

\begin{tabular}{|c|c|c|c|c|c|}
\hline Case & Age/sex & $\begin{array}{c}\text { Initial } \\
\text { presentation }\end{array}$ & Location of mycotic aneurysm & Treatment & Outcome \\
\hline Hill et al. ${ }^{6)}$ & 64/male & $\mathrm{ICH}$ & NR & Conservative therapy & $\mathrm{D}$ \\
\hline Morito et al. ${ }^{7)}$ & $24 /$ male & $\mathrm{ICH}$ & Distal MCA & TAE (NBCA) & GR \\
\hline Remirez et al. ${ }^{8)}$ & $55 /$ male & $\mathrm{SAH}$ & MCA & TAE (NBCA) & NR \\
\hline Voruganti et al. ${ }^{9)}$ & 56/female & ASDH/ICH & Distal MCA, distal PCA & Coil embolization & $\mathrm{SD}$ \\
\hline \multirow[t]{3}{*}{ Lee et al. ${ }^{10)}$} & $37 /$ male & $\mathrm{SAH}$ & MCA (M3-M4) & Conservative therapy & NR \\
\hline & $41 /$ male & $\mathrm{SAH}$ & MCA (M3), left ACA (A3) & Conservative therapy & $\mathrm{SD}$ \\
\hline & 58/female & SAH/IVH & MCA (M4-M5) & Conservative therapy & $\mathrm{SD}$ \\
\hline \multirow[t]{3}{*}{ Trachtenberg et al. ${ }^{16)}$} & 48/female & $\mathrm{ICH}$ & MCA (angular branch) & TAE (Onyx) & $\mathrm{D}$ \\
\hline & 45/male & $\mathrm{ICH}$ & $\begin{array}{l}\text { MCA (posterior temporal } \\
\text { branch) }\end{array}$ & TAE (Onyx) & $\mathrm{D}$ \\
\hline & 47/male & $\mathrm{ICH}$ & PCA & TAE (Onyx) & $\mathrm{D}$ \\
\hline Cheng-Ching et al. ${ }^{20)}$ & NR/NR & $\mathrm{ICH}$ & PCA (P4) & Hematoma evacuation & NR \\
\hline Present case & 49/male & $\mathrm{ICH}$ & MCA (parietooccipital artery) & TAE (NBCA) & GR \\
\hline
\end{tabular}

ACA: anterior cerebral artery, ASDH: acute subdural hemorrhage, D: death, GR: good recovery, ICH: intracranial hemorrhage, IVH: intraventricular hemorrhage, LVAD: left ventricular assist device, MCA: middle cerebral artery, NBCA: N-butyl 2-cyanoacrylate, NR: not reported, PCA: posterior cerebral artery, SAH: subarachnoid hemorrhage, SD: severe disability, TAE: trans-arterial embolization. 
altered hemodynamics and vasculature due to continuous blood flow, ${ }^{7,9)}$ these features might lead to poor outcomes of the intracranial mycotic aneurysm after LVAD implantation.

TAE with NBCA for a distally located intracranial mycotic aneurysm after LVAD implantation is a procedure of choice. It is difficult to discontinue the anticoagulant therapy during LVAD placement. ${ }^{18)}$ Therefore, performing an endovascular procedure, instead of trapping the aneurysm with craniotomy, is feasible for treating intracranial mycotic aneurysms, except in patients who have intracranial hemorrhage accompanied by a mass effect. Generally, liquid embolic agents were used instead of coils to treat distally located intracranial mycotic aneurysms because of their simultaneous sealing of lesions and deliverability of microcatheters to these distal lesions. ${ }^{19)}$ According to previous reports, $\mathrm{NBCA}^{20)}$ and ethylene-vinyl alcohol copolymer (Onyx, eV3 Neurovascular, Irvine, CA, USA) ${ }^{21)}$ were used for the treatment of distally located intracranial mycotic aneurysms. Owing to the poor general condition of patients with LVAD placement, including their cardiac function, NBCA might be considered more suitable than Onyx, as a liquid embolic agent; it does not require induction of general anesthesia, thereby avoiding adverse effects of general anesthesia. In our case, NBCA was used as an alternative treatment under local anesthesia. Although we were concerned about the patient's movement and possible pain during the injection of NBCA under local anesthesia, no such issue was encountered.

Pulsation of the vessels in patients with LVAD placement is not palpable due to continuous-flow LVAD. The use of continuous-flow LVAD with pulsatile LVAD in recent years ${ }^{22)}$ could be the cause of difficulty in puncturing arteries and one of the problems in performing endovascular treatment in patients with LVAD placement. In our case, the trans-brachial approach was selected, instead of the trans-femoral approach, because of the tortuous anatomy of the origin of the innominate artery and implant of the aortic arch. When puncturing the brachial arteries in patients with LVAD placement, particularly those with small caliber and pulseless arteries, using ultrasound guidance could help visualize the vessel lumen and secure the target vessels.

\section{Conclusion}

TAE using liquid embolic materials is effective in the treatment of intracranial mycotic aneurysm after LVAD implantation, which requires systemic anticoagulation. Besides, a minimally invasive procedure could be obtained with NBCA under local anesthesia.

\section{Conflicts of Interest Disclosure}

All the authors report no conflicts of interest concerning this article.

\section{References}

1) Rose EA, Gelijns AC, Moskowitz AJ, et al.: Long-term use of a left ventricular assist device for end-stage heart failure. $N$ Engl J Med 345: 1435-1443, 2001

2) Tattevin P, Flécher E, Auffret V, et al.: Risk factors and prognostic impact of left ventricular assist deviceassociated infections. Am Heart J 214: 69-76, 2019

3) Kirklin JK, Naftel DC, Pagani FD, et al.: Seventh INTERMACS annual report: 15,000 patients and counting. J Heart Lung Transplant 34: 1495-1504, 2015

4) Eckman PM, John R: Bleeding and thrombosis in patients with continuous-flow ventricular assist devices. Circulation 125: 3038-3047, 2012

5) Patel S, Rizvi SSA, Choi JH, et al.: Management and outcomes of left ventricular assist device-associated endocarditis: a systematic review. Ann Cardiothorac Surg 8: 600-609, 2019

6) Hill JA, Mokadam NA, Rakita RM: Intracranial mycotic aneurysm associated with left ventricular assist device infection. Ann Thorac Surg 98: 1088-1089, 2014

7) Morito H, Nishimura T, Ando M, et al.: Endovascular treatment of cerebral hemorrhage in a patient with a left ventricular assist device: report of a case. Surg Today 44: 957-960, 2014

8) Remirez JM, Sabet Y, Baca M, et al.: Mycotic intracranial aneurysm secondary to left ventricular assist device infection. J Vasc Interv Neurol 9: 23-25, 2017

9) Voruganti D, Gajurel K, Bhama JK, Cotarlan V: Ruptured intracranial mycotic aneurysm in infective endocarditis with left ventricular assist device and implantable cardiac defibrillator device: a clinical course. Transplant Proc 50: 4064-4066, 2018

10) Lee T, Buletko AB, Matthew J, Cho SM: Bloodstream infection is associated with subarachnoid hemorrhage and infectious intracranial aneurysm in left ventricular assist device. Perfusion 35: 117-120, 2020

11) Ducruet AF, Hickman ZL, Zacharia BE, et al.: Intracranial infectious aneurysms: a comprehensive review. Neurosurg Rev 33: 37-46, 2010

12) Hui FK, Bain M, Obuchowski NA, et al.: Mycotic aneurysm detection rates with cerebral angiography in patients with infective endocarditis. J Neurointerv Surg 7: 449-452, 2015

13) Frontera JA, Starling R, Cho SM, et al.: Risk factors, mortality, and timing of ischemic and hemorrhagic stroke with left ventricular assist devices. J Heart Lung Transplant 36: 673-683, 2017 
14) Sakaguchi M, Kitagawa K, Okazaki S, et al.: Sulcus subarachnoid hemorrhage is a common stroke subtype in patients with implanted left ventricular assist devices. Eur J Neurol 22: 1088-1093, 2015

15) Yoshioka D, Sakaniwa R, Toda K, et al.: Relationship between bacteremia and hemorrhagic stroke in patients with continuous-flow left ventricular assist device. Circ J 82: 448-456, 2018

16) Trachtenberg BH, Cordero-Reyes AM, Aldeiri M, et al.: Persistent blood stream infection in patients supported with a continuous-flow left ventricular assist device is associated with an increased risk of cerebrovascular accidents. J Card Fail 21: 119-125, 2015

17) Singla A, Fargen K, Blackburn S, et al.: National treatment practices in the management of infectious intracranial aneurysms and infective endocarditis. J Neurointerv Surg 8: 741-746, 2016

18) Shiga T, Kinugawa $K$, Hatano $M$, et al.: Age and preoperative total bilirubin level can stratify prognosis after extracorporeal pulsatile left ventricular assist device implantation. Circ J 75: 122-128, 2011
19) Chapot R, Houdart E, Saint-Maurice JP, et al.: Endovascular treatment of cerebral mycotic aneurysms. Radiology 222: 389-396, 2002

20) Cheng-Ching E, John S, Bain M, et al.: Endovascular embolization of intracranial infectious aneurysms in patients undergoing open heart surgery using n-butyl cyanoacrylate. Interv Neurol 6: 82-89, 2017

21) Grandhi R, Zwagerman NT, Linares G, et al.: Onyx embolization of infectious intracranial aneurysms. $J$ Neurointerv Surg 6: 353-356, 2014

22) Topkara VK, Kondareddy S, Malik F, et al.: Infectious complications in patients with left ventricular assist device: etiology and outcomes in the continuous-flow era. Ann Thorac Surg 90: 1270-1277, 2010

Corresponding author: Tatsuya Ishikawa, MD, PhD

Department of Neurosurgery, Tokyo Women's Medical University, 8-1 Kawadacho, Shinjuku-ku, Tokyo 162-8666, Japan.

e-mail: tishikawa@twmu.ac.jp 